\title{
Patterns of spatial genetic structures in Aedes albopictus (Diptera: Culicidae) populations in China
}

Yong Wei ${ }^{1}$, Jiatian Wang ${ }^{1}$, Zhangyao Song ${ }^{1}$, Yulan He ${ }^{1}$, Zihao Zheng ${ }^{1}$, Peiyang Fan ${ }^{1}$, Dizi Yang ${ }^{1}$, Guofa Zhou², Daibin Zhong ${ }^{2}$ and Xueli Zheng ${ }^{1 *}$

\begin{abstract}
Background: The Asian tiger mosquito, Aedes albopictus, is one of the 100 worst invasive species in the world and the vector for several arboviruses including dengue, Zika and chikungunya viruses. Understanding the population spatial genetic structure, migration, and gene flow of vector species is critical to effectively preventing and controlling vector-borne diseases. Little is known about the population structure and genetic differentiation of native Ae. albopictus in China. The aim of this study was to examine the patterns of the spatial genetic structures of native Ae. albopictus populations, and their relationship to dengue incidence, on a large geographical scale.
\end{abstract}

Methods: During 2016-2018, adult female Ae. albopictus mosquitoes were collected by human landing catch (HLC) or human-bait sweep-net collections in 34 localities across China. Thirteen microsatellite markers were used to examine the patterns of genetic diversity, population structure, and gene flow among native Ae. albopictus populations. The correlation between population genetic indices and dengue incidence was also examined.

Results: A total of 153 distinct alleles were identified at the 13 microsatellite loci in the tested populations. All loci were polymorphic, with the number of distinct alleles ranging from eight to sixteen. Genetic parameters such as PIC, heterozygosity, allelic richness and fixation index $\left(F_{S T}\right)$ revealed highly polymorphic markers, high genetic diversity, and low population genetic differentiation. In addition, Bayesian analysis of population structure showed two distinct genetic groups in southern-western and eastern-central-northern China. The Mantel test indicated a positive correlation between genetic distance and geographical distance $\left(R^{2}=0.245, P=0.01\right)$. STRUCTURE analysis, PCoA and GLS interpolation analysis indicated that Ae. albopictus populations in China were regionally clustered. Gene flow and relatedness estimates were generally high between populations. We observed no correlation between population genetic indices of microsatellite loci in Ae. albopictus populations and dengue incidence.

Conclusion: Strong gene flow probably assisted by human activities inhibited population differentiation and promoted genetic diversity among populations of Ae. albopictus. This may represent a potential risk of rapid spread of mosquito-borne diseases. The spatial genetic structure, coupled with the association between genetic indices and dengue incidence, may have important implications for understanding the epidemiology, prevention, and control of vector-borne diseases.

Keywords: Aedes albopictus, Microsatellite, Genetic diversity, Population structure, Gene flow, Dengue

\footnotetext{
*Correspondence: zhengxueli2001@126.com

1 Department of Pathogen Biology, School of Public Health, Southern

Medical University, Guangzhou, China

Full list of author information is available at the end of the article
} 


\section{Background}

Aedes (Stegomyia) albopictus (Skuse, 1894) originated in Southeast Asia and spread to several islands in the Pacific and the Indian Oceans during the 17th and 18th centuries [1]. It was discovered in Albania in Europe in 1979 [2], the USA and Brazil in North and South America in 1986 [3, 4], Fiji in Oceania in 1990 [5] and Nigeria in Africa in 1992 [6]. Global warming, winter diapause, and human-aided transportation have contributed to the global invasion of Ae. albopictus [7-9].

As a vector of over 20 arboviruses [10] and one of the 100 worst invasive species in the world [11], Ae. albopictus poses serious public health concerns for arbovirusrelated disease outbreaks. In China, dengue has been a threat for 40 years, since the first reported outbreak in 1978 [12]. Local dengue transmission has been identified in Guangdong, Guangxi, Hainan, Yunnan, Fujian, Zhejiang and Henan provinces [13]. Aedes albopictus and $A e$ e aegypti are two important vector species responsible for dengue transmission in China. Aedes albopictus is the most predominant species and has been found in nearly one third of China [14]. This species has a wide range of distribution from north of $41^{\circ} \mathrm{N}$ latitude to the southern reaches of the country, while the distribution of Ae. aegypti is limited to small areas of southern China, including Hainan, Guangdong, Guangxi and Yunnan provinces $[15,16]$. Li et al. [17] reported that Ae. aegypti was found only in two sites (Maoming, Guangdong and Sanya, Hainan) of the 26 mosquito surveillance sites in China. The relative proportion of Ae. albopictus to Ae. aegypti was > 20:1 in the two sites during 2005-2015, while the proportion of Ae. albopictus to Ae. aegypti was approximately 1:2 in 2014 in Jinghong city, Yunnan Province [18]. Aedes albopictus has been reported to be the sole mosquito vector for dengue transmission in Guangzhou, with no presence of Ae. aegypti identified over the past three decades [19]. The strong adaptability of Ae. albopictus has contributed to the reemergence and wide spread of dengue [20] and the outbreaks of mosquito-borne diseases have spread with the expansion of mosquito habitats [21]. Vector surveillance, dispersal monitoring, and control play an important role in controlling outbreaks [22].

Molecular markers can provide abundant information that is critical to studying the sources and routes of vector invasions $[11,23]$. As the second generation of DNA markers, microsatellites or simple sequence repeats (SSRs), consisting of short tandem repeats of 1-6 nucleotides, are widely distributed in the genomes of animals and plants [24]. Due to the advantages of simple operation, easy detection, good reproducibility, high polymorphism, and the inheritance of Mendelian codominance [25], microsatellite markers have been utilized to evaluate genetic diversity and population structure, and identify invasions of Ae. albopictus [22, 26, 27]. Multiple microsatellite markers for Ae. albopictus have been isolated previously, and there are more than 50 microsatellites applied in population genetic studies of Ae. albopictus [11]. Although mitochondrial DNA markers are rapidly evolving, non-recombining, maternally inherited, and exhibit high rates of mutation, mtDNA is not a strictly neutral marker; strong directional selection on mtDNA sequence has been reported in several insect species [28-30]. In order to obtain more accurate and detailed information on genetic structure, large-scale multi-site samplings should be conducted, and neutral microsatellite markers should be used to investigate Ae. albopictus population genetics.

The present study was designed to address the following questions: (i) What is the level of genetic diversity and population differentiation in and between Ae. albopictus populations in China?; (ii) What are the patterns of colonization and dispersal (or gene flow) of Ae. albopictus in China?; (iii) Is there any association between genetic diversity indices and local dengue incidence? To address these questions, extensive mosquito samplings and a set of thirteen microsatellite loci were used in the study. The data gained from this study could provide useful information for understanding the epidemiology, prevention, and control of vector-borne diseases.

\section{Methods \\ Mosquito sampling and DNA extraction}

From 2016 to 2018, adult female Ae. albopictus mosquitoes were collected by human landing catch (HLC) or human-bait sweep-net collections in 34 locations in 19 provinces across northern and southern China, including Hainan Island (Fig. 1, Table 1). The abbreviations of the 34 locations are as follows: LS, Lingshui; QZ, Qiongzhong; BS, Baisha; CM, Chengmai; ZJ, Zhanjiang; MM, Maoming; SZ, Shenzhen; GZ, Guangzhou; JY, Jieyang; MZ, Meizhou; JH, Jinghong; WZ, Wuzhou; RJ, Rongjiang; GY, Guiyang; CQ, Chongqing; TN, Tongnan; MS, Meishan; CS, Changsha; GAZ, Ganzhou; NC, Nanchang; WH, Wuhan; JZ, Jingzhou; AK, Ankang; LX, Lanxi; SX, Shaoxing; HZ, Hangzhou; ZMD, Zhumadian; KF, Kaifeng; LY, Linyi; LF, Linfen; SJZ, Shijiazhuang; TJ, Tianjin; BJ, Beijing; and SY, Shenyang.

In each location, 8-12 households or collection points at $400-3000 \mathrm{~m}$ apart were selected randomly for adult mosquito collections to minimize sibling bias. Approximately 30 Ae. albopictus female mosquitoes from each location with 2-3 individuals per collection point were used for DNA extraction and genetic analysis. Local dengue surveillance data from the 19 provinces during 2011-2015 were obtained from the 


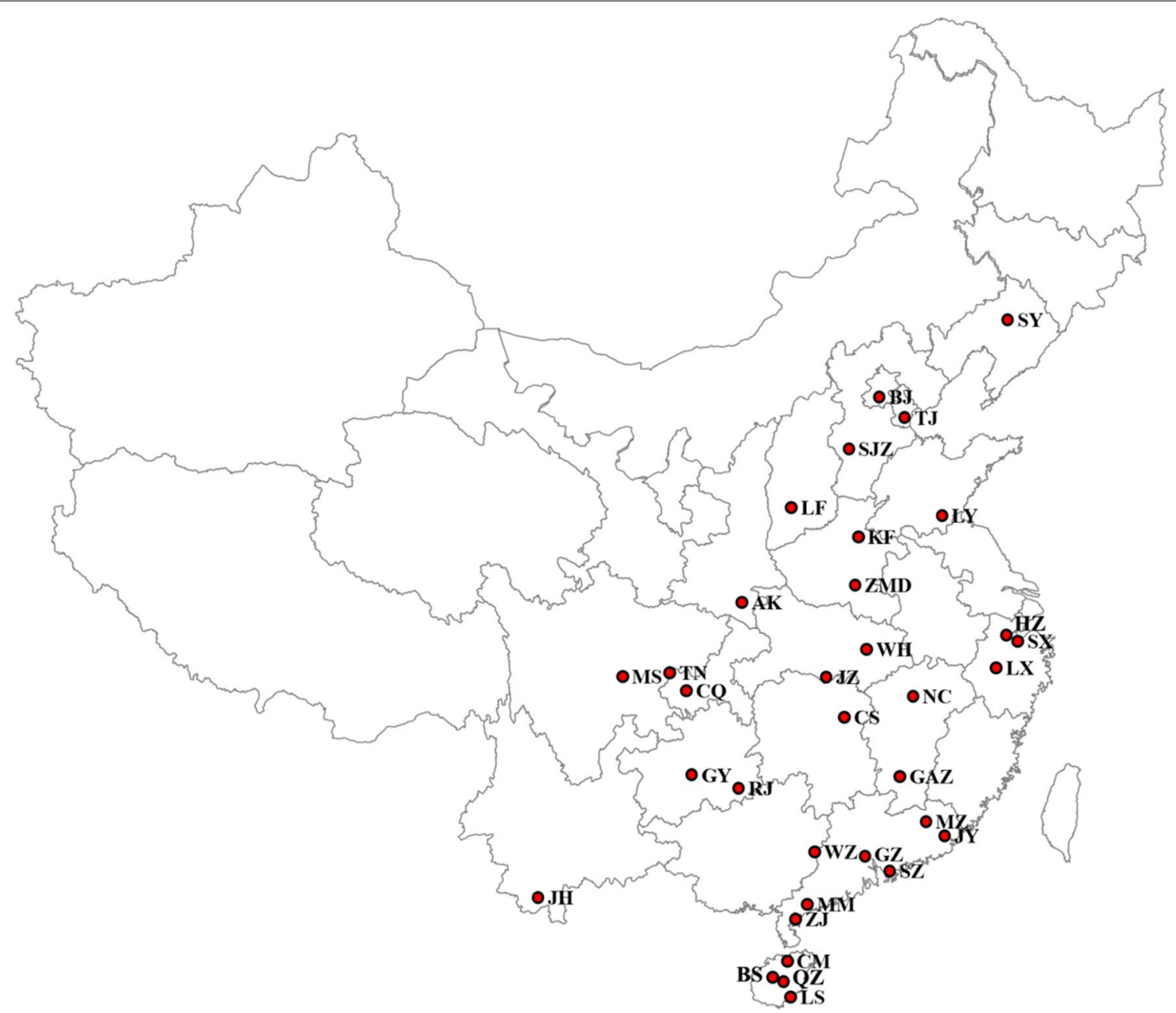

Fig. 1 Geographical locations of Ae. albopictus sampling sites in China. Abbreviations: LS, Lingshui; QZ, Qiongzhong; BS, Baisha; CM, Chengmai; ZJ, Zhanjiang; MM, Maoming; SZ, Shenzhen; GZ, Guangzhou; JY, Jieyang; MZ, Meizhou; JH, Jinghong; WZ, Wuzhou; RJ, Rongjiang; GY, Guiyang; CQ, Chongqing; TN, Tongnan; MS, Meishan; CS, Changsha; GAZ, Ganzhou; NC, Nanchang; WH, Wuhan; JZ, Jingzhou; AK, Ankang; LX, Lanxi; SX, Shaoxing; HZ, Hangzhou; ZMD, Zhumadian; KF, Kaifeng; LY, Linyi; LF, Linfen; SJZ, Shijiazhuang; TJ, Tianjin; BJ, Beijing; SY, Shenyang

website (http://www.phsciencedata.cn/Share/en/index .jsp) of the Public Health Science Data Center managed by the Chinese Center for Disease Control and Prevention. The 19 provinces include those with frequent dengue fever outbreaks in the past 30 years, including Guangdong, Guangxi, Yunnan, Zhejiang and Hainan, as well as provinces with dengue outbreaks in recent years, including Hubei, Hunan, Guizhou and Jiangxi. Other provinces have imported cases, including Shanxi, Shandong and Liaoning. The collected specimens were identified morphologically to Ae. albopictus, and samples were stored in $70 \%$ ethanol. Total genomic DNA was individually extracted using the Insect DNA Kit (Omega Bio-tek, GA, USA), following the manufacturer's protocol.

\section{Cryptic species identification and Wolbachia infection}

Aedes albopictus cryptic species identification was performed by DNA sequencing of the mitochondrial gene cytochrome $c$ oxidase subunit 1 ( $\operatorname{cox} 1)$ for the samples collected in Guangxi Province, where the cryptic species have been detected previously [31]. The Wolbachia infection status of individual mosquitoes was examined by PCR amplification of Wolbachia ribosomal DNA using a previously published method [31].

\section{Microsatellite genotyping}

A set of thirteen microsatellite markers was used to examine the patterns of genetic diversity, population structure, and gene flow among the native mosquito populations. These markers, which were developed in 
Table 1 Sampling information of Ae. albopictus collection in China

\begin{tabular}{|c|c|c|c|c|c|c|}
\hline Province & Sample sites & Abbreviation & Sample size & Latitude & Longitude & Collection date \\
\hline \multirow[t]{4}{*}{ Hainan } & Lingshui & LS & 32 & $18^{\circ} 30^{\prime} 27^{\prime \prime} \mathrm{N}$ & $110^{\circ} 01^{\prime} 59^{\prime \prime} \mathrm{E}$ & August 2016 \\
\hline & Qiongzhong & QZ & 32 & $19^{\circ} 02^{\prime} 06^{\prime \prime} \mathrm{N}$ & $109^{\circ} 50^{\prime} 03^{\prime \prime} \mathrm{E}$ & August 2016 \\
\hline & Baisha & BS & 22 & $19^{\circ} 13^{\prime 3} 7^{\prime \prime} \mathrm{N}$ & $109^{\circ} 26^{\prime} 51^{\prime \prime} \mathrm{E}$ & August 2016 \\
\hline & Chengmai & CM & 32 & $19^{\circ} 44^{\prime} 25^{\prime \prime} \mathrm{N}$ & $110^{\circ} 00^{\prime} 02^{\prime \prime} \mathrm{E}$ & September 2016 \\
\hline \multirow[t]{6}{*}{ Guangdong } & Zhanjiang & ZJ & 32 & $21^{\circ} 05^{\prime} 37^{\prime \prime} \mathrm{N}$ & $109^{\circ} 42^{\prime} 60^{\prime \prime} \mathrm{E}$ & September 2018 \\
\hline & Maoming & MM & 28 & $21^{\circ} 31^{\prime} 55^{\prime \prime} \mathrm{N}$ & $111^{\circ} 0^{\prime} 31^{\prime \prime} \mathrm{E}$ & August 2018 \\
\hline & Shenzhen & $\mathrm{SZ}$ & 32 & $22^{\circ} 32^{\prime} 26^{\prime \prime} \mathrm{N}$ & $113^{\circ} 59^{\prime} 56^{\prime \prime} \mathrm{E}$ & September 2018 \\
\hline & Guangzhou & $\mathrm{GZ}$ & 32 & $23^{\circ} 11^{\prime} 15^{\prime \prime} \mathrm{N}$ & $113^{\circ} 19^{\prime} 42^{\prime \prime} \mathrm{E}$ & June 2018 \\
\hline & Jieyang & JY & 32 & $23^{\circ} 37^{\prime} 43^{\prime \prime} \mathrm{N}$ & $116^{\circ} 16^{\prime} 43^{\prime \prime} \mathrm{E}$ & August 2018 \\
\hline & Meizhou & $M Z$ & 32 & $24^{\circ} 08^{\prime} 11^{\prime \prime} \mathrm{N}$ & $115^{\circ} 40^{\prime} 26^{\prime \prime} \mathrm{E}$ & August 2018 \\
\hline Yunnan & Jinghong & $J \mathrm{H}$ & 25 & $22^{\circ} 0^{\prime} 32^{\prime \prime} \mathrm{N}$ & $100^{\circ} 48^{\prime} 0^{\prime \prime} \mathrm{E}$ & April 2018 \\
\hline Guangxi & Wuzhou & WZ & 33 & $23^{\circ} 22^{\prime} 51^{\prime \prime} \mathrm{N}$ & $110^{\circ} 54^{\prime} 58^{\prime \prime} \mathrm{E}$ & October 2018 \\
\hline \multirow[t]{2}{*}{ Guizhou } & Rongjiang & RJ & 32 & $25^{\circ} 56^{\prime} 31^{\prime \prime} \mathrm{N}$ & $108^{\circ} 31^{\prime} 40^{\prime \prime} \mathrm{E}$ & August 2018 \\
\hline & Guiyang & GY & 31 & $26^{\circ} 33^{\prime} 24^{\prime \prime} \mathrm{N}$ & $106^{\circ} 45^{\prime} 36^{\prime \prime} \mathrm{E}$ & August 2018 \\
\hline \multirow[t]{2}{*}{ Chongqing } & Chongqing & $\mathrm{CQ}$ & 32 & $29^{\circ} 30^{\prime} 32^{\prime \prime} \mathrm{N}$ & $106^{\circ} 28^{\prime} 36^{\prime \prime} \mathrm{E}$ & June 2018 \\
\hline & Tongnan & $\mathrm{TN}$ & 28 & $30^{\circ} 09^{\prime} 59^{\prime \prime} \mathrm{N}$ & $105^{\circ} 49^{\prime} 54^{\prime \prime} \mathrm{E}$ & June 2018 \\
\hline Sichuan & Meishan & MS & 32 & $30^{\circ} 11^{\prime} 55^{\prime \prime} \mathrm{N}$ & $103^{\circ} 52^{\prime} 01^{\prime \prime} \mathrm{E}$ & September 2018 \\
\hline Hunan & Changsha & CS & 32 & $28^{\circ} 14^{\prime} 25^{\prime \prime} \mathrm{N}$ & $113^{\circ} 04^{\prime} 15^{\prime \prime} \mathrm{E}$ & July 2018 \\
\hline \multirow[t]{2}{*}{ Jiangxi } & Ganzhou & GAZ & 32 & $25^{\circ} 52^{\prime} 18^{\prime \prime} \mathrm{N}$ & $115^{\circ} 01^{\prime 2} 29^{\prime \prime} \mathrm{E}$ & September 2018 \\
\hline & Nanchang & NC & 30 & $28^{\circ} 40^{\prime} 54^{\prime \prime} \mathrm{N}$ & $115^{\circ} 54^{\prime} 27^{\prime \prime} \mathrm{E}$ & July 2018 \\
\hline \multirow[t]{2}{*}{ Hubei } & Wuhan & WH & 31 & $30^{\circ} 30^{\prime} 30^{\prime \prime} \mathrm{N}$ & $114^{\circ} 22^{\prime} 39^{\prime \prime} \mathrm{E}$ & July 2018 \\
\hline & Jingzhou & $J Z$ & 28 & $29^{\circ} 50^{\prime} 11^{\prime \prime} \mathrm{N}$ & $112^{\circ} 28^{\prime} 15^{\prime \prime} \mathrm{E}$ & July 2018 \\
\hline Shanxi (west) & Ankang & AK & 18 & $32^{\circ} 36^{\prime} 21^{\prime \prime} \mathrm{N}$ & $108^{\circ} 25^{\prime} 57^{\prime \prime} \mathrm{E}$ & September 2018 \\
\hline \multirow[t]{3}{*}{ Zhejiang } & Lanxi & $L X$ & 32 & $29^{\circ} 13^{\prime} 16^{\prime \prime} \mathrm{N}$ & $119^{\circ} 28^{\prime} 35^{\prime \prime} \mathrm{E}$ & October 2018 \\
\hline & Shaoxing & $S X$ & 27 & $29^{\circ} 50^{\prime} 51^{\prime \prime} \mathrm{N}$ & $120^{\circ} 30^{\prime} 04^{\prime \prime} \mathrm{E}$ & August 2018 \\
\hline & Hangzhou & $\mathrm{HZ}$ & 25 & $30^{\circ} 18^{\prime} 42^{\prime \prime} \mathrm{N}$ & $120^{\circ} 07^{\prime} 09^{\prime \prime} \mathrm{E}$ & August 2018 \\
\hline \multirow[t]{2}{*}{ Henan } & Zhumadian & ZMD & 32 & $32^{\circ} 58^{\prime} 34^{\prime \prime} \mathrm{N}$ & $114^{\circ} 0^{\prime} 27^{\prime \prime} \mathrm{E}$ & August 2018 \\
\hline & Kaifeng & KF & 32 & $34^{\circ} 47^{\prime} 53^{\prime \prime} \mathrm{N}$ & $114^{\circ} 18^{\prime} 05^{\prime \prime} \mathrm{E}$ & August 2018 \\
\hline Shandong & Linyi & LY & 31 & $35^{\circ} 20^{\prime} 18^{\prime \prime} \mathrm{N}$ & $118^{\circ} 09^{\prime} 06^{\prime \prime} \mathrm{E}$ & August 2018 \\
\hline Shanxi (east) & Linfen & LF & 32 & $36^{\circ} 10^{\prime} 34^{\prime \prime} \mathrm{N}$ & $111^{\circ} 36^{\prime} 01^{\prime \prime} \mathrm{E}$ & September 2018 \\
\hline Hebei & Shijiazhuang & SJZ & 32 & $37^{\circ} 54^{\prime} 55^{\prime \prime} \mathrm{N}$ & $114^{\circ} 27^{\prime} 49^{\prime \prime} \mathrm{E}$ & August 2018 \\
\hline Tianjin & Tianjin & $\mathrm{TJ}$ & 32 & $39^{\circ} 06^{\prime} 19^{\prime \prime} \mathrm{N}$ & $117^{\circ} 10^{\prime} 41^{\prime \prime} \mathrm{E}$ & August 2018 \\
\hline Beijing & Beijing & BJ & 30 & $39^{\circ} 51^{\prime} 36^{\prime \prime} \mathrm{N}$ & $116^{\circ} 11^{\prime} 45^{\prime \prime} \mathrm{E}$ & August 2018 \\
\hline Liaoning & Shenyang & SY & 28 & $41^{\circ} 52^{\prime} 28^{\prime \prime} \mathrm{N}$ & $123^{\circ} 33^{\prime} 36^{\prime \prime} \mathrm{E}$ & August 2018 \\
\hline
\end{tabular}

previous studies, included 3 dinucleotide and 10 trinucleotide loci $[27,32]$. The PCR reaction mixture consisted of $40 \mathrm{ng}$ genomic DNA, $7.5 \mu \mathrm{l} 2 \times$ PCR Master Mix (Promega, Madison, WI, USA), $0.05 \mu \mathrm{l}(10 \mu \mathrm{M}) \mathrm{M} 13$ tagged forward primer, $0.2 \mu \mathrm{l}(10 \mu \mathrm{M})$ reverse primer, and $0.2 \mu \mathrm{l}$ M13 tagged fluorescent dye (FAM, HEX or TAMRA), in a final volume of $15 \mu \mathrm{l}$. The PCR cycling conditions were as follows: $95{ }^{\circ} \mathrm{C}$ for $5 \mathrm{~min}$; 30 cycles of $95{ }^{\circ} \mathrm{C}$ for $30 \mathrm{~s}$, $58{ }^{\circ} \mathrm{C}$ for $40 \mathrm{~s}$, and $72{ }^{\circ} \mathrm{C}$ for $45 \mathrm{~s} ; 8$ cycles of $95{ }^{\circ} \mathrm{C}$ for $30 \mathrm{~s}, 53{ }^{\circ} \mathrm{C}$ for $40 \mathrm{~s}$, and $72{ }^{\circ} \mathrm{C}$ for $45 \mathrm{~s}$; and a final extension at $72{ }^{\circ} \mathrm{C}$ for $10 \mathrm{~min}$. PCR products were sent to the Beijing Genomics Institute (BGI, Shenzhen, China) and processed in an automatic sequencer ABI 3730 (Applied Biosystems, Foster City, CA, USA). Allele sizes for each locus were read with GeneMarker software (version 2.6.3) [33].

\section{Data analysis}

\section{Analysis of pairwise relatedness}

Pairwise genetic relatedness between individuals was examined by LRM estimator [34] and QGM estimator [35] using GenAlex v.6.5 [36] to detect kinship within and between Ae. albopictus populations. The coefficient of relationship, $r \geq 0.25$ for LRM and $r \geq 0.5$ for QGM 
was used to define a full sibling relationship (parents and offspring, or siblings that share the same parents), and a value of $0.125<r<0.25$ for LRM and $0.25<r<0.5$ for QGM indicates a half sibling (one shared parent). In order to reduce the siblings bias within population for analysis of genetic structure, we selected only one individual from each putative full-sibling group within any population.

\section{Genetic diversity and differentiation}

Genetic variation within each locality was estimated in terms of the average number of alleles $(\mathrm{Na})$, effective number of alleles $(\mathrm{Ne})$, inbreeding coefficient $\left(F_{\mathrm{IS}}\right)$, fixation index $\left(F_{\mathrm{ST}}\right)$, observed heterozygosity $(\mathrm{Ho})$ and expected heterozygosity $(\mathrm{He})$ using GenAlEx v.6.5 [36]. The number of migrants per generation, or gene flow, was calculated using the following formula: $\mathrm{Nm}=\left(1 / F_{\mathrm{ST}}-1\right) / 4$ [37]. Polymorphic information content (PIC) across all sixteen loci was assessed using Microsatellite Toolkit [38]. The possible presence of null alleles was checked at a population level for each marker using Micro-Checker (version 2.2.3) [39]. To determine whether the individuals in each study location were sufficient for the research, the mean number of alleles per locus $(\mathrm{Na})$ for each population was calculated with a rarefaction method using Allelic Diversity Analyzer (version 1.0) [40]. Deviation from Hardy-Weinberg equilibrium (HWE) and linkage disequilibrium (LD) were computed using GENEPOP version 4.7 [41, 42]. Analysis of molecular variance (AMOVA) was performed using Arlequin version 3.5.2.2 [43]. To detect bottlenecks, the Wilcoxon test for heterozygosity excess was conducted with a two-phase mutation (TPM, 70\% proportion of stepwisemutation model in TPM, 30\% variance for TPM, 1000 iterations) in BOTTLENECK v.1.2.02 [44, 45]. Genetic landscape shape (GLS) interpolation analysis was conducted using Alleles In Space (AIS) software based on the pairwise genetic and geographical distance matrices [46]. Results of GLS interpolation analysis were imported into Surfer software to produce the contour map [47]. A Mantel test on geographical and genetic distance (pairwise phiPT) was performed in GenAlEx v.6.5 using 9999 permutations. The correlation between geographical and genetic distance was plotted and the correlation coefficient $(r)$ as well as $R$-squared were estimated using GenAlEx v.6.5.

\section{Population structure}

Geographical population structure was evaluated using the Bayesian clustering method in STRUCTURE v.2.3 [48], which identifies the most probable number of genetic clusters $(\mathrm{K})$ and assigns individuals to these clusters. We conducted different runs using different datasets for further clustering. For each dataset, the most likely number of clusters $(\mathrm{K})$ was determined by conducting 5 independent runs for each $K$, from $K=1$ to the maximum number of populations included in the analysis. Each run assumed an admixture model and independent allele frequencies using a 'burn-in' value of 50,000 iterations followed by 200,000 repetitions. The optimal number of clusters (K) was determined using the Delta $K$ method of Evanno et al. [49] in the online version of Structure Harvester v.0.6.94 [50]. Then we used a 'burnin' of 100,000 and runtime of 2,000,000 generations per iteration (20 iterations) for the optimal K-values [26]. To compile data from the 20 iterations for the independent values of $\mathrm{K}$, we used the Greedy algorithm in CLUMPP v.1.1.2 with 1000 replicates [51]. The results were plotted in DISTRUCT v.1.1 [52]. Relationships among populations were assessed using principal coordinates analysis (PCoA) in GenAlEx v.6.5.

\section{Correlation analysis between genetic indices and dengue incidence}

Dengue incidence was calculated as the number of cases per $100,000,000$ people. Due to the high variation in the number of cases, the data were rescaled with a log-transformation using the equation $\operatorname{Ln}(\mu)$, where $\mu$ is the number of cases per 100,000,000 people. Pearson's correlation coefficient was used to analyze the correlation between dengue incidence after transformation and genetic indices, including allelic richness, private allelic richness, effective alleles, Shannon's information index, observed heterozygosity and inbreeding coefficient. The correlation analysis was performed using SPSS version 22. A significance level at $P<0.05$ was set for all statistical tests, and the sequential Bonferroni correction [53] was used when significant correlations were detected between the paired data.

\section{Results}

Detection of Ae. albopictus cryptic species and Wolbachia infection

No Ae. albopictus cryptic species was detected in the samples collected from Guangxi Province. The cox1 haplotype was identical with the sequences on GenBank (KY765450, KY765452 and KY765455). All the samples showed positive infection of Wolbachia with type A and/ or type B. The majority of samples (>93\%) were infected with type A and type B together, only a few samples were infected with type A $(5.1 \%)$ or type B (1.6\%) (Additional file 1: Table S1).

\section{Microsatellite analysis of genetic variability and diversity}

Genotypes at 13 microsatellite loci were determined for 1023 Ae. albopictus specimens collected in 34 locations 
(Table 1). We compared the detailed pairwise relatedness of all specimens within and between populations (Additional file 2: Table S2). Genetic relatedness of full sibling among individuals within population were observed in 16 out of the 34 Ae. albopictus populations with high proportion of kinship in Wuzhou, Beijing and Shenyang populations. Full sibling relationships were also found among 32 (94\%) of the 34 Ae. albopictus populations with the highest proportion of kinship between Beijing and Shenyang. There were 559 pairs $(0.107 \%)$ of half siblings and 68 pairs $(0.013 \%)$ of full siblings among individual within populations, and 5882 pairs $(1.125 \%)$ of half siblings and 82 pairs $(0.016 \%)$ of full siblings among individuals between populations (Table 2). We excluded 46 samples of full siblings in collection sites and used the data from 977 Ae. albopictus specimens to conduct further analysis. In total, 153 alleles were obtained. All loci were polymorphic, showing several distinct alleles ranging from eight (Aealbmic9) to sixteen (ALB-TRI-6) with an average of 11.769 per locus (Table 2). Micro-Checker results suggest that locus Aealbmic12 has a high probability of null alleles, as its estimated null allele frequency is 0.317 calculated by Brookfield's method [54]. There is no evidence of null alleles for loci Aealbmic9, Aealbmic8, Aealbmic6, ALB-DI-6 and ALB-TRI-33 (Table 2). The remaining loci exhibited signs of having null alleles, but their estimated frequency was lower than 0.200 (Table 2). PIC was high, with values ranging from 0.447 (ALB-DI-4) to 0.846 (ALB-TRI-6) (mean value 0.691) (Table 2). Shannon's information index was consistent with PIC, ranging from 0.880 (ALB-DI-4) to 1.973 (ALB-TRI-6) (mean value of 1.645) (Table 2). Among the 442 pairs tested for Hardy-Weinberg equilibrium (HWE) at each locus per population site after Bonferroni corrections, 158 pairs significantly departed from HWE $(P<0.05)$, where 146 of these significant departures indicated heterozygosity deficits (Additional file 3: Table S3). No locus-by-locus

Table 2 Genetic relatedness between samples in Ae. albopictus population

\begin{tabular}{lll}
\hline Kinship & $n$ & Percentage \\
\hline Within populations & & \\
Half sibling & 559 & 0.107 \\
Full sibling & 68 & 0.013 \\
Total & 627 & 0.120 \\
Between populations & & \\
Half sibling & 5882 & 1.125 \\
Full sibling & 82 & 0.016 \\
Total & 5964 & 1.141 \\
Total pairwise comparisons & 522,753 & \\
\hline
\end{tabular}

Abbreviation: $\mathrm{n}$, number of comparisons pair showed significance consistently across all locations, though 165 of 2652 (6.22\%) pairs tested for linkage disequilibrium (LD) remained significant (Additional file 4: Table S4). Fifty-three (11.99\%) pairs tested for HWE lost the significance after Bonferroni corrections, so did the $161(6.07 \%)$ pairs tested for LD.

The genetic diversity and difference analysis of $A e$. albopictus showed that the mean number of alleles per locus at each location ranged from 5.308 (SY) to 9.000 (LS), with an average of 6.912, and the allelic richness ranged from 4.327 (SY) to 7.561 (LS), with an average of 5.995 (Additional file 5: Table S5). Allelic richness increased as the sample size increased (Additional file 6: Figure S1). The $\mathrm{Ho}$ values for each locus ranged from 0.394 (ALB-DI-4) to 0.775 (Aealbmic9), and the $\mathrm{He}$ values for each locus ranged from 0.456 (Aealbmic6) to 0.824 (ALB-TRI-6) (Table 3). The Ho values for each location ranged from $0.501(\mathrm{QZ})$ to $0.690(\mathrm{SZ})$, and the $\mathrm{He}$ values for each location ranged from 0.619 (SY) to 0.763 (LS) (Additional file 5: Table S5). Except in the location $\mathrm{SZ}$, the $\mathrm{He}$ values were higher than the $H o$ values in all locations. Using the TPM model, tests for recent population bottlenecks based on gene diversity and allele frequency distribution were not significant, except in the SJZ population (Additional file 5: Table S5).

\section{Genetic structure and differentiation}

Based on Bayesian clustering analysis and the Delta $\mathrm{K}$ method, each population in this study was assigned to one of two genetically differentiated groups $(\mathrm{K}=2$, Additional file 7: Figure S2a), which splits southern and western China from a group comprising the eastern, central and northern populations (Fig. 2a). Some admixture was observed between the groups. A further independent Bayesian clustering analysis and higher resolution were obtained by analyzing the structure plot for the two groups. In the first group, the southern populations can be separated from the western populations at $\mathrm{K}=2$ (Fig. 2b, Additional file 7: Figure S2b). In the second group, the central, eastern, central northern, and northern clusters were divided at $\mathrm{K}=3$ (Fig. 2c, Additional file 7: Figure S2c). Additionally, the results of principal coordinates analysis (Fig. 3) illustrated the genetic similarities among different populations in each region, which was similar to the results from STRUCTURE. Based on these results, we divided the 34 populations into five clusters: southern (LS, QZ, BS, CM, ZJ, MM, JH, SZ, GZ, JY, MZ, GAZ, WZ), western (RJ, GY, CQ, TN, MS), central (CS, NC, WH, JZ, AK), eastern (LX, SX, HZ), and northern (ZMD, KF, LY, LF, SJZ, TJ, BJ, SY). The AMOVA results (Table 4) indicate that the majority of the variation in Ae. albopictus was found among individuals and individuals within populations, accounting for 
Table 3 Genetic indices for genetic markers of Ae. albopictus from China

\begin{tabular}{lllllll}
\hline Locus & No. of alleles & $\begin{array}{l}\text { Estimated null allele } \\
\text { frequency }\end{array}$ & PIC & SI & Ho \\
\hline Aealbmic9 & 8 & - & 0.642 & 1.309 & 0.775 & 0.672 \\
Aealbmic10 & 9 & 0.137 & 0.547 & 1.051 & 0.573 & 0.586 \\
Aealbmic8 & 11 & - & 0.816 & 1.785 & 0.761 & 0.809 \\
Aealbmic12 & 11 & 0.317 & 0.819 & 1.850 & 0.574 & 0.812 \\
Aealbmic6 & 10 & - & 0.453 & 0.947 & 0.462 & 0.456 \\
Aealbmic5 & 14 & 0.108 & 0.661 & 1.364 & 0.570 & 0.667 \\
Aealbmic16 & 15 & 0.102 & 0.716 & 1.591 & 0.599 & 0.708 \\
ALB-TRI-6 & 16 & 0.091 & 0.846 & 1.973 & 0.629 & 0.824 \\
ALB-DI-6 & 13 & - & 0.744 & 1.569 & 0.485 & 0.743 \\
ALB-DI-4 & 9 & 0.139 & 0.447 & 0.880 & 0.394 & 0.466 \\
Aealbmic3 & 14 & 0.154 & 0.815 & 1.846 & 0.664 & 0.791 \\
ALB-TRI-33 & 10 & - & 0.722 & 1.451 & 0.721 & 0.721 \\
Aealbmic1 & 13 & 0.122 & 0.752 & 1.475 & 0.544 & 0.596 \\
Mean & 11.769 & & 0.691 & \\
\hline
\end{tabular}

Abbreviations: PIC, polymorphic information content; SI, Shannon's index; Ho, observed heterozygosity; He, expected heterozygosity

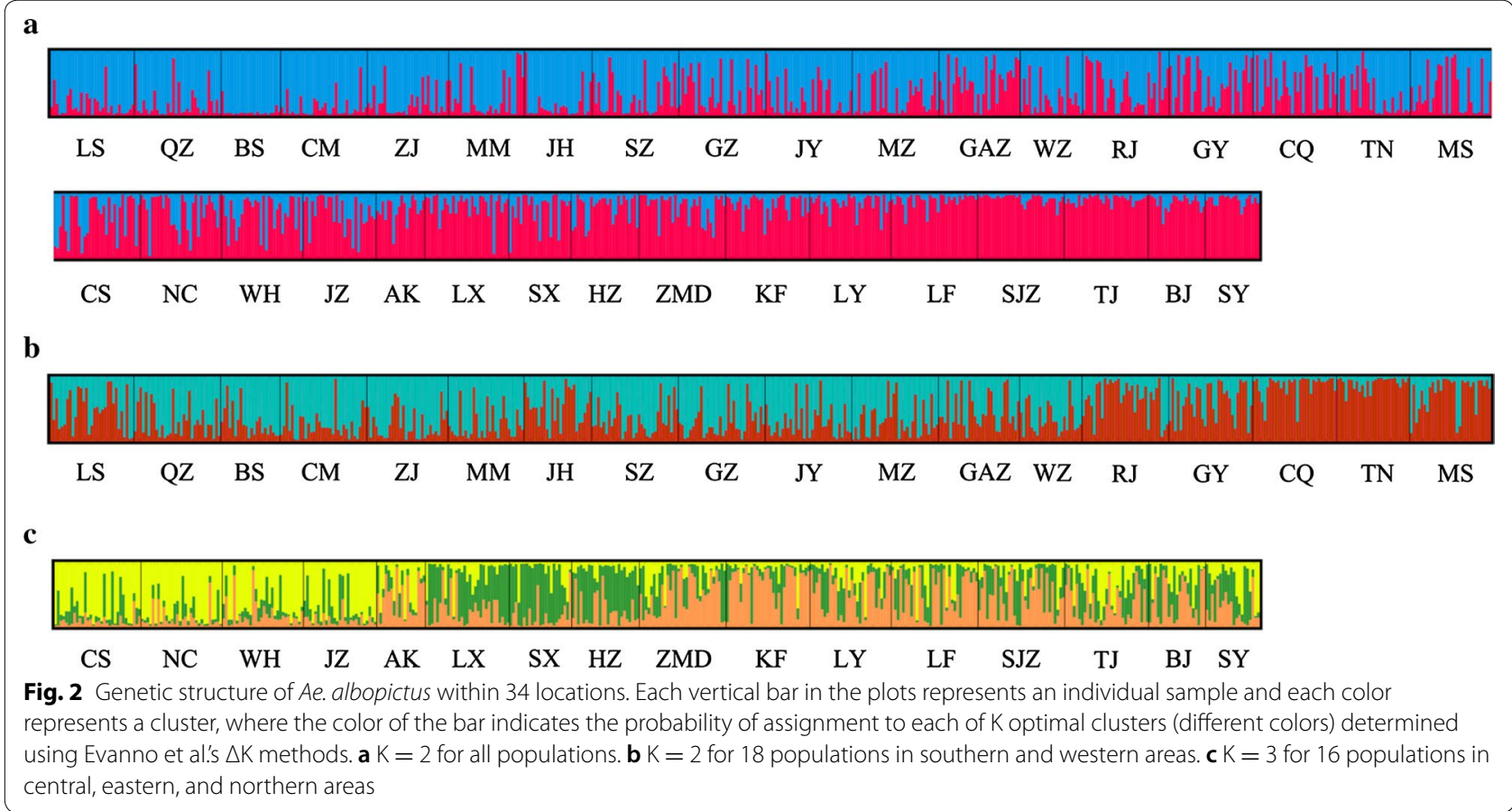

$83.16 \%$ and $14.21 \%$ of the variation, respectively, while variations among groups and populations within groups accounted for only $1.30 \%$ and $1.32 \%$ of the total variation, respectively. Fisher's exact test showed that there was significant genetic variation at these four levels.

The pairwise $F_{\mathrm{ST}}$ values of Ae. albopictus ranged from 0.005 to 0.049 , with 500 out of $561(89.13 \%) F_{\mathrm{ST}}$ values showing significant genetic differentiation and one losing the significance after Bonferroni correction (Additional file 8: Table S6). However, the gene flow calculated by $F_{\mathrm{ST}}$ showed that the minimum value of $\mathrm{Nm}$ between populations is 4.88 (Additional file 8: Table S6), suggesting strong gene flow. The genetic landscape shape analysis identified major potential gene flow barriers (Fig. 4). The high peaks of differentiation were found in southern and southwestern China, and low genetic differentiation was 


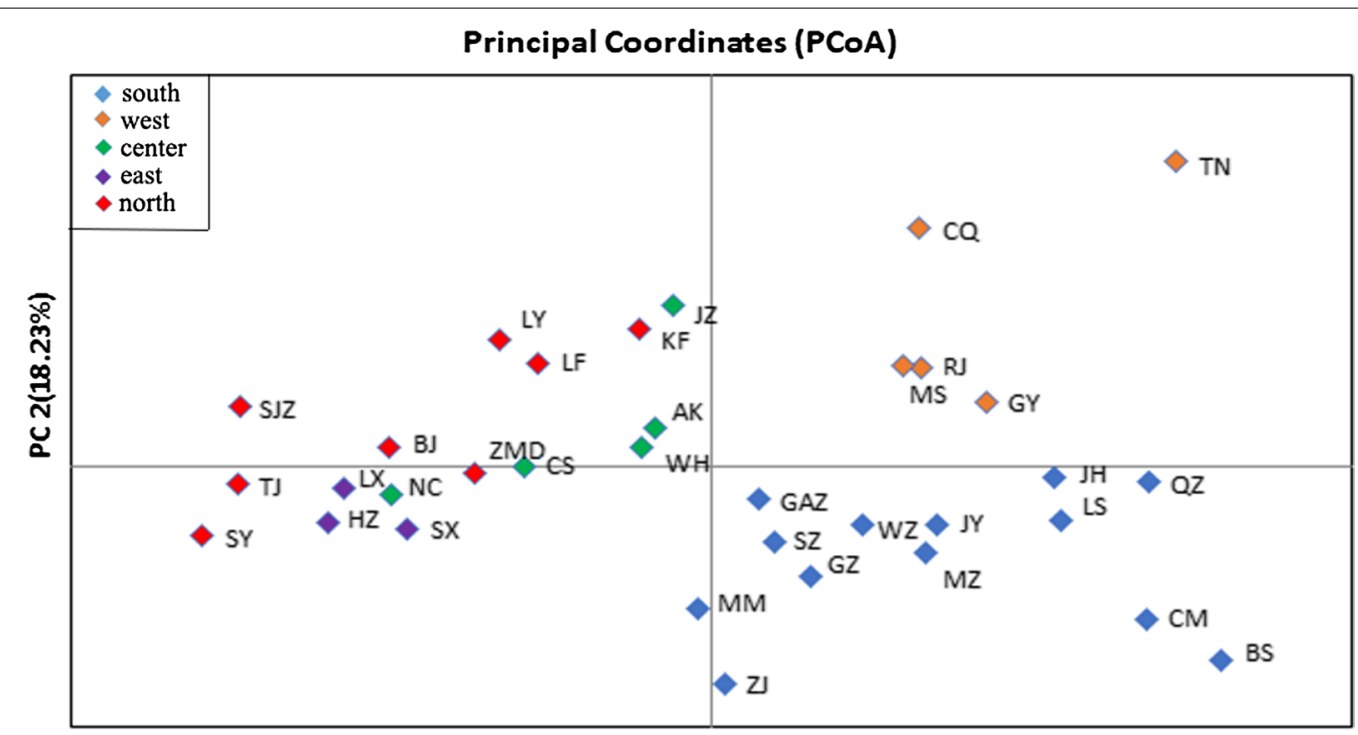

PC1(20.52\%)

Fig. 3 Principal coordinates analysis based on co-dominant genotypic genetic distance, displaying genetic similarities among populations of Ae. albopictus sampled from different regions in China

Table 4 Analysis of molecular variance of populations from seven different clusters

\begin{tabular}{|c|c|c|c|c|c|c|}
\hline Source of variation & $d f$ & Sum of squares & $\begin{array}{l}\text { Variance } \\
\text { components }\end{array}$ & $\begin{array}{l}\text { Percentage of } \\
\text { variation }\end{array}$ & $P$-value & Fixation index \\
\hline Among groups & 4 & 121.507 & 0.060 & 1.30 & $P<0.0001$ & $F_{C T}=0.013$ \\
\hline Among populations within groups & 29 & 250.076 & 0.061 & 1.32 & $P<0.0001$ & $F_{S C}=0.013$ \\
\hline Among individuals within populations & 943 & 4837.406 & 0.653 & 14.21 & $P<0.0001$ & $F_{1 S}=0.146$ \\
\hline Within individuals & 977 & 3735.000 & 3.823 & 83.16 & $P<0.0001$ & $F_{\Pi T}=0.168$ \\
\hline Total & 1953 & 8943.989 & 4.597 & & & \\
\hline
\end{tabular}

Abbreviations: $d f$, degrees of freedom

detected among populations in the eastern and northern regions (Fig. 4). The Mantel test showed statistically significant correlation $\left(R^{2}=0.245, P=0.01\right)$ between the genetic distance (estimated as $F_{\mathrm{ST}} /\left(1-F_{\mathrm{ST}}\right)$ ) and geographical distance (estimated as Ln $(\mathrm{km})$ ) between populations (Fig. 5, Additional file 9: Table S7).

\section{Correlation between population genetic indices and dengue incidence}

In order to explore the association between genetic structure and vector-borne disease, we conducted Pearson's correlation analysis of six genetic indices and annual dengue incidence from 2011 to 2015 in different provinces (Table 5). Allelic richness $(r=0.530, P=0.020)$ and private allelic richness $(r=0.551, P=0.015)$ showed a positive correlation with dengue incidence after logtransformations. However, the significance was lost after the Bonferroni correction for multiple testing (adjusted $P$-value $<0.00238$ ). Shannon's information index $(r=0.455, P=0.051)$, effective alleles $(r=0.353$, $P=0.139)$, observed heterozygosity $(r=0.210$, $P=0.388)$ and inbreeding coefficient $(r=0.089$, $P=0.717)$ showed no statistically significant correlation to dengue incidence after log transformations.

\section{Discussion}

Few studies have reported the population structure and genetic diversity of Ae. albopictus in China, and they have focused on using mitochondrial DNA markers to analyze genetic diversity, regional structure, mainly in populations in southern China, or they have used a limited sampling size $[31,55]$. For example, Guo et al. [31] sequenced the mitochondrial DNA cytochrome $c$ oxidase subunit 1 (cox1) gene of 140 Ae. albopictus from 14 populations in southern China, and Zhang et al. [55] sequenced cox1 of 119 Ae. albopictus from 17 populations in China. The results of these studies showed low genetic diversity and 


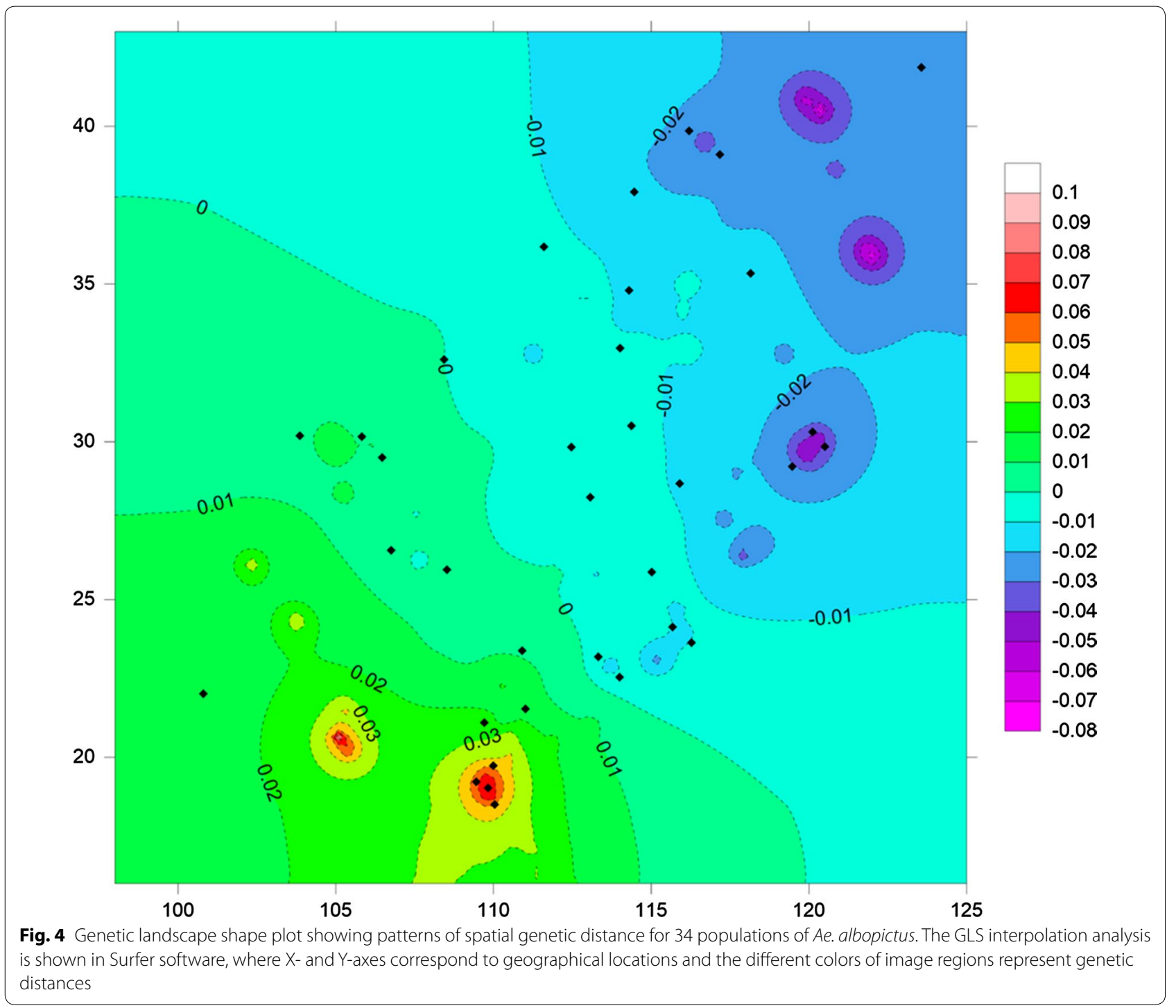

shallow genetic differentiation between some of the study populations. In the present study we included many new study sites and populations, such as those in the northern (SY, SJZ, TJ), western (MS, TN), and central areas (WH, JZ), etc. The 34 collecting sites were widely distributed, providing comprehensive information on the population structure of Ae. albopictus throughout China. The correlation of average allele richness and sample size showed that when sample size $<15$, allele richness increased rapidly as sample size increased, whereas it increased only slightly when sample size $>25$. The number of samples in most populations was within the optimum range (25-30) [56]. The mean number of alleles per locus and the allelic richness were higher in southern populations than in northern populations, and the diversity of alleles gradually decreased from south to north. The climate in northern temperate areas may affect the life traits of $A e$. albopictus. The period in which the climate is suitable for mosquito survival is longer in southern subtropical areas than in northern areas. The relatively low temperatures and dry climate in the north may not be suitable for mosquito survival, reproduction, and dispersal, resulting in lower allele richness and population diversity in northern populations $[57,58]$.

A major drawback of using microsatellite markers in population genetic studies is the potential impact of null alleles, such as reducing population genetic diversity and increasing genetic differentiation among populations [59, 60]. Microsatellite null alleles are commonly more frequent in arthropods than in other species [61-63]; this may be a result of large effective population size, as species with large effective population size have relatively large proportions of individuals with null alleles [64]. Many studies have determined that a null allele frequency 


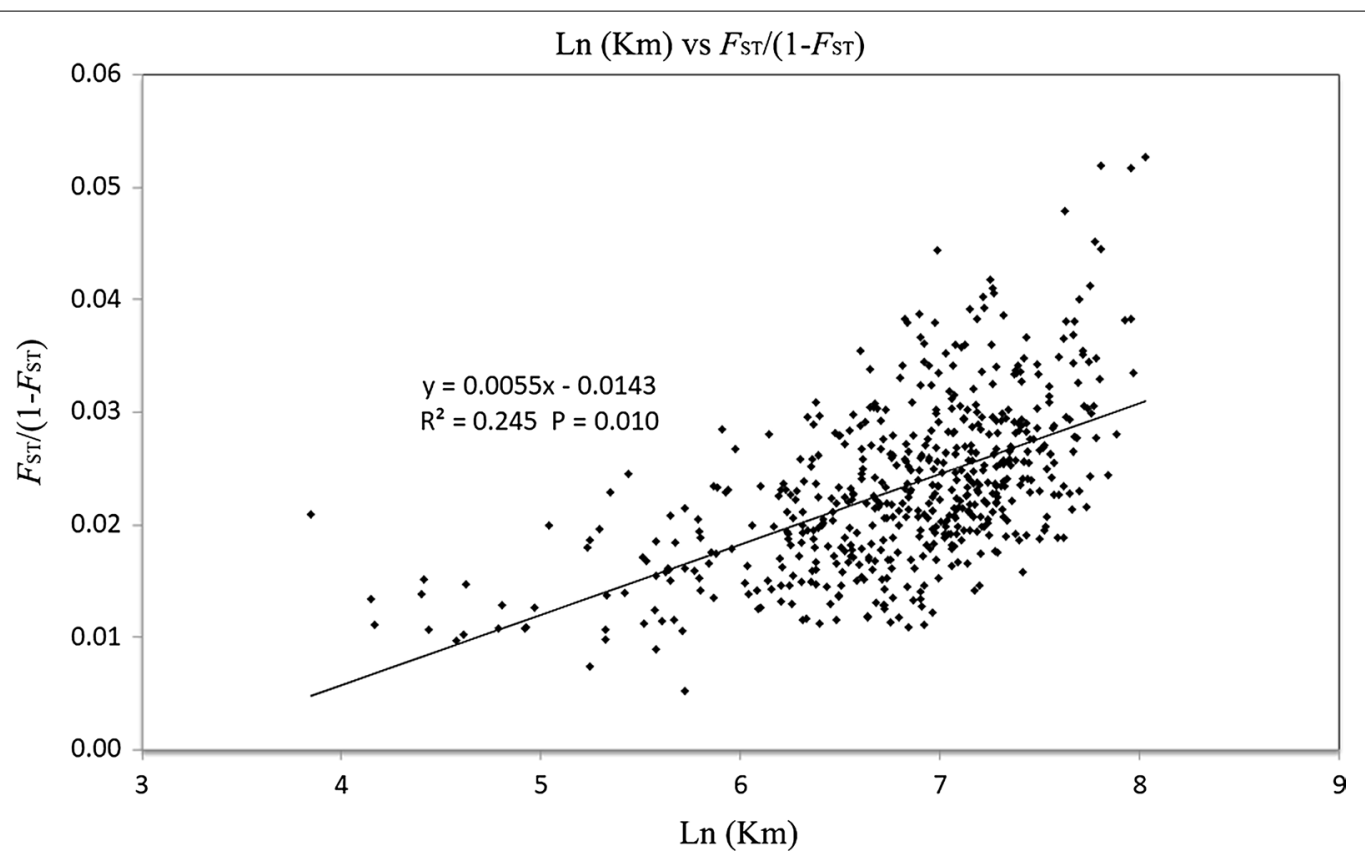

Fig. 5 Correlation between genetic distance $\left[F_{S T} /\left(1-F_{S T}\right)\right]$ and geographical distance $[\mathrm{Ln}(\mathrm{km})]$ for all locations in China. The relationship was significant (Mantel test; $R^{2}=0.245, P=0.01$ )

$<0.2$ has no significant effect on the accuracy of data analysis, and its effect on genetic diversity and genetic structure may be even less $[64,65]$. In our study, null allele frequency was $<0.2$ or absent, except at locus Aealbmic12. Expected heterozygosity is a common parameter for measuring the genetic polymorphism of a population [66]. Takezaki \& Nei [67] suggested that an expected microsatellite heterozygosity between $0.5-0.8$ indicates that the population genetic polymorphism is high. In the present study, the expected heterozygosity in all populations was between $0.6-0.8$, and most were higher than the observed heterozygosity, indicating a deficit of heterozygosity except in the SZ and SY populations [68]. Insecticides have been used frequently in some areas, and fragmentation of habitats can intensify inbreeding within small populations, leading to a heterozygosity deficit. For bottleneck testing, we used the two-phase mutation (TPM) model, which is considered the best-fit for microsatellite data [44]. Our bottleneck test results indicated that only the SJZ population may have experienced a temporary bottleneck; this may be related to the wide use of insecticides [69] or sharp climatic changes [70] in the local area causing a decline in local populations.

Our results showed that $F_{\mathrm{ST}}$-values in all pairwise populations were not high, but most were significantly different, indicating genetic differentiation between populations. The low genetic distance and pairwise $F_{\mathrm{ST}}$ may be related to the fact that most of the study sites are central cities in their provinces and transportation between them is convenient. Jinghong, a busy tourist destination close to the Southeast Asian countries, connects to many cities via highways and airways but has no trains or high-speed rail, which explains the relatively high pairwise $F_{\mathrm{ST}}$ between Jinghong and other cities. Low $F_{\mathrm{ST}^{-}}$ values with no significant difference may be attributed to the close distance, convenient transportation, high traffic, and similar environmental conditions between populations [71]. China is home to an ancestral population of Ae. albopictus, and most populations in China have been stable for a long time [22]. $\mathrm{Nm}>1$ indicates that a population is sufficient to prevent the occurrence of genetic differentiation [72]. Our results showed strong gene flow between populations, which can reduce genetic differentiation. The results of genetic relatedness showed the individuals among different collection sites with long distance had different degrees of kinship, indicating potential human-aided dispersal of Ae. albopictus across the country. Extensive mosquito dispersal, probably aided by human transportation between these regions, also helps explain the low differentiation and the possible clustering between different regions.

There is some limitation for microsatellites compared to SNPs, the third generation DNA markers. Weaker separation between populations was usually obtained with microsatellites compared to SNPs. A total of 934 SNPs showed stronger power in distinguishing closely related 
Table 5 The correlation of dengue incidence with six genetic indices among Ae. albopictus populations in different provinces

\begin{tabular}{|c|c|c|c|c|c|c|c|}
\hline Province & Allelic richness & $\begin{array}{l}\text { Private allelic } \\
\text { richness }\end{array}$ & $\mathrm{Ne}$ & $\mathrm{SI}$ & Ho & $F_{1 S}$ & $\begin{array}{l}\text { Annual } \\
\text { dengue cases }\end{array}$ \\
\hline Hainan & 7.171 & 0.181 & 4.754 & 1.748 & 0.548 & 0.278 & 56 \\
\hline Guangdong & 6.453 & 0.047 & 3.983 & 1.559 & 0.633 & 0.093 & 9541 \\
\hline Yunnan & 7.263 & 0.418 & 4.718 & 1.682 & 0.592 & 0.204 & 1548 \\
\hline Guangxi & 6.183 & 0.094 & 3.542 & 1.459 & 0.591 & 0.152 & 371 \\
\hline Guizhou & 6.106 & 0.005 & 3.784 & 1.487 & 0.577 & 0.159 & 3 \\
\hline Chongqing & 6.530 & 0.029 & 4.485 & 1.586 & 0.647 & 0.081 & 42 \\
\hline Sichuan & 6.320 & 0.016 & 4.000 & 1.530 & 0.561 & 0.214 & 20 \\
\hline Hunan & 5.506 & 0.025 & 3.539 & 1.359 & 0.518 & 0.209 & 37 \\
\hline Jiangxi & 6.379 & 0.090 & 3.982 & 1.539 & 0.553 & 0.195 & 16 \\
\hline Hubei & 5.994 & 0.052 & 3.949 & 1.490 & 0.546 & 0.213 & 23 \\
\hline Shanxi (west) & 5.579 & 0.000 & 3.657 & 1.394 & 0.644 & 0.028 & 11 \\
\hline Zhejiang & 5.704 & 0.129 & 3.678 & 1.409 & 0.628 & 0.018 & 59 \\
\hline Henan & 6.134 & 0.094 & 3.981 & 1.530 & 0.658 & 0.059 & 17 \\
\hline Shandong & 5.811 & 0.002 & 3.917 & 1.447 & 0.582 & 0.136 & 9 \\
\hline Shanxi (east) & 5.697 & 0.011 & 3.785 & 1.422 & 0.551 & 0.183 & 1 \\
\hline Hebei & 5.827 & 0.001 & 3.855 & 1.434 & 0.564 & 0.133 & 8 \\
\hline Tianjin & 5.713 & 0.002 & 3.435 & 1.359 & 0.633 & 0.031 & 4 \\
\hline Beijing & 5.653 & 0.000 & 3.455 & 1.379 & 0.600 & 0.076 & 69 \\
\hline Liaoning & 4.904 & 0.001 & 3.183 & 1.236 & 0.597 & 0.001 & 7 \\
\hline $\begin{array}{l}\text { Pearson's correlation } \\
\text { coefficient }^{\mathrm{b}}\end{array}$ & 0.530 & 0.551 & 0.353 & 0.455 & 0.210 & 0.089 & \\
\hline$P$-value & 0.020 & 0.015 & 0.139 & 0.051 & 0.388 & 0.717 & \\
\hline
\end{tabular}

a From 2011 to 2015 (per 100,000,000 persons)

b The annual dengue case data was rescaled with a log transformation using the equation $\mathrm{Ln}(\mu)$, where $\mu$ is the number of cases per $100,000,000$ people Abbreviations: Ne, effective number of alleles; SI, Shannon's index; Ho, observed heterozygosity; $F_{\mathrm{IS}}$, inbreeding coefficient

individuals at a small spatial scale than 8 microsatellites in Ae. aegypti populations [73]. A total of 2185 SNPs outperformed nine highly variable microsatellites in parentage and kinship assignment in An. darlingi populations, and the conventional approaches based on microsatellites may underestimate overall genetic distances in closely related vector populations [74]. The pairwise $F_{\mathrm{ST}}$ or the degree of differentiation in the present study may be smaller for microsatellites than if SNPs have been used. Therefore, we might overestimate the gene flow between populations through the analysis of microsatellites. Mitochondrial DNA has been widely used for the study of molecular taxonomy, phylogenetic relationships and population genetics in mosquitoes [75-77]. However, microsatellites outperformed mtDNA in assessing spatial genetic structures. Only microsatellites not mtDNA showed small but positive and significant isolation-bydistance patterns in An. sinensis populations [78]. No genetic structure was detected through mtDNA data while a high level of genetic structure was detected using the microsatellite markers inside polymorphic inversions in An. arabiensis populations [79]. Guo et al. [31] discovered the cryptic species in Wuzhou using mitochondrial DNA cytochrome $c$ oxidase subunit 1 (cox1) gene to analyze population genetics of Ae. albopictus in southern China. We also have collected Ae. albopictus population from a different village in Wuzhou, but we did not find any individual belonging to a cryptic species by cox 1 sequencing. One of the possible reasons might be due to location-specific or seasonal abundance features of the cryptic species.

The spread of dengue fever has been affected not only by the climate (e.g. temperature, rainfall, relative humidity and sunshine) $[80,81]$, but also by the vector indices (e.g. container, house, Breteau, pupal or adult indices) and genetic factors of the populations [82-84]. Aedes aegypti population from French Polynesia was more susceptible to infection and had higher ability to transmit DENV-1 than Ae aegypti population from New Caledonia in the same experimental environment [84]. The genetic background of mosquito populations could influence the vector competence of mosquitoes, and the genetic indices can be utilized as a potential predictor of local dengue epidemiology [85]. The six genetic indices 
are the main indices of population genetics, which could directly reflect the actual genetic variability and diversity of local mosquitoes. But they were not significantly correlated with dengue incidence during 2011-2015. One possible reason might be that dengue outbreaks are mainly affected by climate and environment rather than genetic background of Ae. albopictus population in China. The other one might be that dengue incidence is associated with other genetic indices or other genetic markers rather than the six indices from 13 microsatellites in this study. One genetic index, the inbreeding coefficient $\left(F_{\mathrm{IS}}\right)$ might be expected to show significant positive correlation to dengue incidence, due to the vertical transmission of dengue virus to mosquito offspring $[86,87]$. This natural transovarial transmission process has been demonstrated in field-collected Ae. aegypti mosquitoes from some different areas [88-90]. The rate of vertical transmission initially increased in the few generations (F1-F2) of Ae. aegypti mosquitoes, and in subsequent generations it was found to be steady until at least the 7th generation through the inbreeding of each generation [91]. We inferred that the inbreeding within the mosquito population might lead to a substantial number of offspring carrying the dengue virus and an increased disease transmission within local areas. Inbreeding coefficient has been found to be positively associated with dengue incidence in Ae. aegypti populations [85]. However, our study detected no significant correlation. One plausible explanation is that the amount of viral infection in the mosquitoes collected in our study is not enough to spread vertically to offspring. In addition, the endosymbiotic bacteria Wolbachia existing in Ae. albopictus, not in Ae. aegypti naturally, has a blocking effect on the vertical transmission of dengue virus [92, 93]. Although the specific mechanism of Wolbachia inhibiting dengue virus is unclear, the cytoplasmic incompatibility $(\mathrm{CI})$ induced by Wolbachia can reduce the mosquito populations [94], and Wolbachia can induce density-dependent inhibition to dengue virus in mosquito cells [95]. At present, mosquitoes transfected with Wolbachia have been applied in the control of mosquitoes and mosquito-borne diseases $[96,97]$. The application would change the population structure and genetic indices of local mosquitoes, and it would require our monitoring. Further research is needed to ascertain on whether these genetic indices could be supplementary indices for the prediction of the local dengue epidemiology.

\section{Conclusions}

This study reported not only the spatial genetic structure of Ae. albopictus but also the correlation of genetic indices with dengue incidence. Our results may have implications for predicting future dengue outbreaks and understanding the epidemiology, prevention and control of vector-borne diseases. Strong gene flow probably assisted by human activities inhibited population differentiation and promoted genetic diversity among Ae. albopictus populations. This may represent a potential risk of rapid spread of mosquito-borne diseases. The data collected in this study, combined with other related factors such as climate, rainfall and human activities, will be valuable for vector control efforts as well as epidemiological prediction and modeling of the incidence and spread of vector-borne diseases.

\section{Supplementary information}

Supplementary information accompanies this paper at https://doi. org/10.1186/s13071-019-3801-4.

Additional file 1: Table S1. The Wolbachia infection status in populations. Additional file 2: Table S2. The pairwise genetic relatedness between individuals.

Additional file 3: Table S3. Analysis of Hardy-Weinberg equilibrium.

Additional file 4: Table S4. Analysis of linkage disequilibrium.

Additional file 5: Table S5. Genetic indices of 34 populations.

Additional file 6: Figure S1. Average allele richness of microsatellite loci in 34 populations.

Additional file 7: Figure S2. Scatter plots of Log probability of the data (Left) and Delta K (Right) for Ae. albopictus populations. Delta K plots are based on the rate of change in the log probability of the data between successive K values. a All populations. b 18 populations in southern and western areas. c 16 populations in central, eastern, central northern, and northern areas.

Additional file 8: Table S6. $F_{\text {ST }}$ and $\mathrm{Nm}$ between 34 populations.

Additional file 9: Table S7. Genetic distance and geographical distance between 34 populations.

\section{Abbreviations}

AMOVA: analysis of molecular variance; PIC: polymorphic information content; SI: Shannon's index; HWE: Hardy-Weinberg equilibrium; LD: linkage disequilibrium.

\section{Acknowledgements}

We would like to thank Yuanhuan Wei, Ke Hu, Yulan Chen, Hao Zhang, Guangsheng Qiu, Weihao Zou, Yan Sun, Yijie Zhao, Denghua Wei, Weigui Ni, Jiayan Xie, Tianrenzheng Zhu and Yueyi Feng for their assistance in collecting mosquito samples from different provinces.

\section{Authors' contributions}

YW, XZ, DZ and GZ conceived and designed the experiments. YW, JW, ZS, YH, $Z Z, P F$ and DY performed the experiments. YW and DZ analyzed the data. $Y W, X Z, D Z$ and GZ wrote and revised the manuscript. All authors read and approved the final manuscript.

Funding

This work was supported by the National Natural Science Foundation of China (No. 31630011) and the Science and Technology Planning Project of Guangzhou (No. 201804020084).

Availability of data and materials

The data sets supporting the results are included within the article and its additional files. 


\section{Ethics approval and consent to participate}

No specific permits were required for the field studies. After explanation of the purposes and activities of the study, oral consent was obtained from the local participating residents prior to mosquito collection. No sites were protected by law and this study did not involve endangered or protected species.

\section{Consent for publication}

Not applicable.

\section{Competing interests}

The authors declare that they have no competing interests.

\section{Author details}

${ }^{1}$ Department of Pathogen Biology, School of Public Health, Southern Medical University, Guangzhou, China. ${ }^{2}$ Program in Public Health, College of Health Sciences, University of California, Irvine, USA.

Received: 27 June 2019 Accepted: 10 November 2019 Published online: 21 November 2019

\section{References}

1. Paupy C, Delatte H, Bagny L, Corbel V, Fontenille D. Aedes albopictus, an arbovirus vector: from the darkness to the light. Microbes Infect. 2009:11:1177-85.

2. Adhami J, Reiter P. Introduction and establishment of Aedes (Stegomyia) albopictus Skuse (Diptera: Culicidae) in Albania. J Am Mosq Control Assoc. 1998;14:340-3.

3. Sprenger D, Wuithiranyagool T. The discovery and distribution of Aedes albopictus in Harris County, Texas. J Am Mosq Control Assoc. 1986;2:217-9.

4. Forattini OP. Identification of Aedes (Stegomyia) albopictus (Skuse) in Brazil. Rev Saude Publica. 1986;20:244-5.

5. Laille M, Fauran P, Rodhain F. The presence of Aedes (Stegomyia) albopic tus in the Fiji Islands. Bull Soc Pathol Exot. 1990;83:394-8.

6. Savage HM, Ezike VI, Nwankwo AC, Spiegel R, Miller BR. First record of breeding populations of Aedes albopictus in continental Africa: implications for arboviral transmission. J Am Mosq Control Assoc. 1992;8:101-3.

7. Poelchau MF, Reynolds JA, Denlinger DL, Elsik CG, Armbruster PA. Transcriptome sequencing as a platform to elucidate molecular components of the diapause response in the Asian tiger mosquito Aedes albopictus. Physiol Entomol. 2013:38:173-81.

8. Jia P, Chen X, Chen J, Lu L, Liu Q, Tan X. How does the dengue vector mosquito Aedes albopictus respond to global warming? Parasites Vectors. 2017;10:140.

9. Li Y, Xu J, Zhong D, Zhang H, Yang W, Zhou G, et al. Evidence for multipleinsecticide resistance in urban Aedes albopictus populations in southern China. Parasites Vectors. 2018;11:4

10. Gratz NG. Critical review of the vector status of Aedes albopictus. Med Vet Entomol. 2004;18:215-27.

11. Goubert C, Minard G, Vieira C, Boulesteix M. Population genetics of the Asian tiger mosquito Aedes albopictus, an invasive vector of human diseases. Heredity. 2016:117:125-34

12. Qiu FX, Gubler DJ, Liu JC, Chen QQ. Dengue in China: a clinical review. Bull World Health Organ. 1993;71:349-59.

13. Sang S, Gu S, Bi P, Yang W, Yang Z, Xu L, et al. Predicting unprecedented dengue outbreak using imported cases and climatic factors in Guangzhou, 2014. PLoS Negl Trop Dis. 2015;9:e0003808.

14. Wu F, Liu Q, Lu L, Wang J, Song X, Ren D. Distribution of Aedes albopictus (Diptera: Culicidae) in northwestern China. Vector Borne Zoonotic Dis. 2011;11:1181-6.

15. Lu L, Lin H, Tian L, Yang W, Sun J, Liu Q. Time series analysis of dengue fever and weather in Guangzhou, China. BMC Public Health. 2009;9:395.

16. Guo YH, Lai SJ, Liu XB, Li GC, Yu HJ, Liu QY. Governmental supervision and rapid detection on dengue vectors: an important role for dengue control in China. Acta Trop. 2016;156:17-21.

17. Li R, Xu L, Bjornstad ON, Liu K, Song T, Chen A, et al. Climate-driven variation in mosquito density predicts the spatiotemporal dynamics of dengue. Proc Natl Acad Sci USA. 2019;116:3624-9.
18. Liu QY, Guo YH. Coexistence of Aedes aegypti and Aedes albopictus in Jinghong City, Yunnan Province: a survey of Aedes aegypti invasion. J Trop Dis. 2016;04:1-6.

19. Jing Q, Wang M. Dengue epidemiology. Glob Health J. 2019;3:37-45.

20. Rezza G. Aedes albopictus and the reemergence of dengue. BMC Public Health. 2012;12:72.

21. Robert MA, Christofferson RC, Silva NJ, Vasquez C, Mores CN, Wearing HJ. Modeling mosquito-borne disease spread in U.S. urbanized areas: the case of dengue in Miami. PLoS ONE. 2016;11:e0161365.

22. Manni M, Guglielmino CR, Scolari F, Vega-Rua A, Failloux AB, Somboon P, et al. Genetic evidence for a worldwide chaotic dispersion pattern of the arbovirus vector, Aedes albopictus. PLoS Negl Trop Dis. 2017;11:e0005332.

23. Guillemaud T, Beaumont MA, Ciosi M, Cornuet JM, Estoup A. Inferring introduction routes of invasive species using approximate Bayesian computation on microsatellite data. Heredity. 2010;104:88-99.

24. Goldstein DB, Pollock DD. Launching microsatellites: a review of mutation processes and methods of phylogenetic interference. J Hered. 1997:88:335-42.

25. Powell W, Morgante M, Andre C, Hanafey M, Vogel J, Tingey S, et al. The comparison of RFLP, RAPD, AFLP and SSR (microsatellite) markers for germplasm analysis. Mol Breed. 1996;2:225-38.

26. Maynard AJ, Ambrose L, Cooper RD, Chow WK, Davis JB, Muzari MO et al. Tiger on the prowl: invasion history and spatio-temporal genetic structure of the Asian tiger mosquito Aedes albopictus (Skuse, 1894) in the Indo-Pacific. PLoS Negl Trop Dis. 2017;11:e0005546.

27. Beebe NW, Ambrose L, Hill LA, Davis JB, Hapgood G, Cooper RD, et al. Tracing the tiger: population genetics provides valuable insights into the Aedes (Stegomyia) albopictus invasion of the Australasian Region. PLoS Negl Trop Dis. 2013;7:e2361

28. Oliveira DC, Raychoudhury R, Lavrov DV, Werren JH. Rapidly evolving mitochondrial genome and directional selection in mitochondrial genes in the parasitic wasp Nasonia (Hymenoptera: Pteromalidae). Mol Biol Evol. 2008:25:2167-80

29. Sun JT, Jin PY, Hoffmann AA, Duan XZ, Dai J, Hu G, et al. Evolutionary divergence of mitochondrial genomes in two Tetranychus species distributed across different climates. Insect Mol Biol. 2018;27:698-709.

30. Krzywinski J, Li C, Morris M, Conn JE, Lima JB, Povoa MM, et al. Analysis of the evolutionary forces shaping mitochondrial genomes of a Neotropical malaria vector complex. Mol Phylogenet Evol. 2011;58:469-77.

31. Guo Y, Song Z, Luo L, Wang Q, Zhou G, Yang D, et al. Molecular evidence for new sympatric cryptic species of Aedes albopictus (Diptera: Culicidae) in China: a new threat from Aedes albopictus subgroup? Parasites Vectors. 2018;11:228.

32. Manni M, Gomulski LM, Aketarawong N, Tait G, Scolari F, Somboon P, et al. Molecular markers for analyses of intraspecific genetic diversity in the Asian tiger mosquito, Aedes albopictus. Parasites Vectors. 2015;8:188.

33. Hulce D, Li X, Snyder-Leiby T, Liu CSJ. GeneMarker ${ }^{\circledR}$ genotyping software: tools to increase the statistical power of DNA fragment analysis. J Biomol Tech. 2011;22:S35.

34. Lynch M, Ritland K. Estimation of pairwise relatedness with molecular markers. Genetics. 1999;152:1753-66.

35. Queller DC, Goodnight KF. Eestimating relatedness using genetic markers. Evolution. 1989:43:258-75.

36. Peakall R, Smouse PE. GenAlEx 6.5: genetic analysis in Excel. Population genetic software for teaching and research-an update. Bioinformatics. 2012;28:2537-9.

37. Slatkin M. Isolation by distance in equilibrium and non-equilibrium populations. Evolution. 1993:47:264-79.

38. Shaibi T, Lattorff HMG, Moritz RFA. A microsatellite DNA toolkit for studying population structure in Apis mellifera. Mol Ecol Resour. 2008:8:1034-6.

39. Van Oosterhout C, Hutchinson WF, Wills DPM, Shipley P. Micro-checker: software for identifying and correcting genotyping errors in microsatellite data. Mol Ecol Notes. 2004;4:535-8.

40. Szpiech ZA, Jakobsson M, Rosenberg NA. ADZE: a rarefaction approach for counting alleles private to combinations of populations. Bioinformatics. 2008:24:2498-504

41. Rousset F. Genepop'007: a complete re-implementation of the genepop software for Windows and Linux. Mol Ecol Resour. 2008;8:103-6.

42. Raymond M, Rousset F. Genepop (version 1.2): population genetics software for exact tests and ecumenicism. J Hered. 1995;86:248-9. 
43. Excoffier L, Lischer HEL. Arlequin suite ver 3.5: a new series of programs to perform population genetics analyses under Linux and Windows. Mol Ecol Resour. 2010;10:564-7.

44. Di Rienzo A, Peterson AC, Garza JC, Valdes AM, Slatkin M, Freimer NB. Mutational processes of simple-sequence repeat loci in human populations. Proc Natl Acad Sci USA. 1994;91:3166-70.

45. Piry S, Luikart G, Cornuet J. BOTTLENECK: a computer program for detecting recent reductions in the effective size using allele frequency data. J Hered. 1999:90:502-3.

46. Miller MP. Alleles in space (AIS): computer software for the joint analysis of interindividual spatial and genetic information. J Hered. 2005;96:722-4.

47. Zheng S, Li S, Huang L, Chen Y. Visualization programming for batch processing of contour maps based on VB and Surfer software. Adv Eng Softw. 2010;41:962-5.

48. Pritchard JK, Stephens M, Donnelly P. Inference of population structure using multilocus genotype data. Genetics. 2000;155:945-59.

49. Evanno G, Regnaut S, Goudet J. Detecting the number of clusters of individuals using the software STRUCTURE: a simulation study. Mol Ecol. 2005; 14:2611-20.

50. Earl DA, Vonholdt BM. Structure Harvester: a website and program for visualizing STRUCTURE output and implementing the Evanno method. Conserv Genet Resour. 2012:4:359-61.

51. Jakobsson M, Rosenberg NA. CLUMPP: a cluster matching and permutation program for dealing with label switching and multimodality in analysis of population structure. Bioinformatics. 2007;23:1801-6.

52. Rosenberg NA. DISTRUCT: a program for the graphical display of population structure. Mol Ecol Notes. 2004:4:137-8.

53. Rice WR. Analyzing tables of statistical tests. Evolution. 1989;43:223-5.

54. Brookfield JF. A simple new method for estimating null allele frequency from heterozygote deficiency. Mol Ecol. 1996;5:453-5.

55. Ruiling Z, Peien L, Xuejun W, Zhong Z. Molecular analysis and genetic diversity of Aedes albopictus (Diptera, Culicidae) from China. Mitochondrial DNA A DNA Mapp Seq Anal. 2018;29:594-9.

56. Hale ML, Burg TM, Steeves TE. Sampling for microsatellite-based population genetic studies: 25 to 30 individuals per population is enough to accurately estimate allele frequencies. PLOS ONE. 2012;7:e45170.

57. Shapiro LLM, Whitehead SA, Thomas MB. Quantifying the effects of temperature on mosquito and parasite traits that determine the transmission potential of human malaria. PLoS Biol. 2017;15:e2003489.

58. Santos J, Meneses BM. An integrated approach for the assessment of the Aedes aegypti and Aedes albopictus global spatial distribution, and determination of the zones susceptible to the development of Zika virus. Acta Trop. 2017;168:80-90.

59. Lehmann T, Hawley WA, Collins FH. An evaluation of evolutionary constraints on microsatellite loci using null alleles. Genetics. 1996;144:1155-63.

60. Paetkau D, Strobeck C. The molecular basis and evolutionary history of a microsatellite null allele in bears. Mol Ecol. 1995;4:519-20

61. Lehmann T, Besansky NJ, Hawley WA, Fahey TG, Kamau L, Collins FH. Microgeographic structure of Anopheles gambiae in western Kenya based on mtDNA and microsatellite loci. Mol Ecol. 1997:6:243-53.

62. Meglecz E, Petenian F, Danchin E, D'Acier AC, Rasplus JY, Faure E. High similarity between flanking regions of different microsatellites detected within each of two species of Lepidoptera: Parnassius apollo and Euphydryas aurinia. Mol Ecol. 2004;13:1693-700.

63. Chapuis MP, Loiseau A, Michalakis Y, Lecoq M, Estoup A. Characterization and PCR multiplexing of polymorphic microsatellite loci for the locust Locusta migratoria. Mol Ecol Notes. 2005;5:554-7.

64. Chapuis MP, Estoup A. Microsatellite null alleles and estimation of population differentiation. Mol Biol Evol. 2007;24:621-31.

65. Dakin EE, Avise JC. Microsatellite null alleles in parentage analysis. Heredity. 2004;93:504-9.

66. Gutiérrez-Espeleta GA, Kalinowski ST, Boyce WM, Hedrick PW. Genetic variation and population structure in desert bighorn sheep: implications for conservation. Conserv Genet. 2000;1:3-15.

67. Takezaki N, Nei M. Genetic distances and reconstruction of phylogenetic trees from microsatellite DNA. Genetics. 1996;144:389-99.

68. Weir BS, Cockerham CC. Estimating F-statistics for the analysis of population structure. Evolution. 1984;38:1358-70.

69. Wondji C, Simard F, Lehmann T, Fondjo E, Same-Ekobo A, Fontenille D. Impact of insecticide-treated bed nets implementation on the genetic structure of Anopheles arabiensis in an area of irrigated rice fields in the Sahelian region of Cameroon. Mol Ecol. 2005;14:3683-93.

70. Mendonca BAA, de Sousa ACB, de Souza AP, Scarpassa VM. Temporal genetic structure of major dengue vector Aedes aegypti from Manaus, Amazonas, Brazil. Acta Trop. 2014;134:80-8.

71. Lehmann T, Hawley WA, Kamau L, Fontenille D, Simard F, Collins FH. Genetic differentiation of Anopheles gambiae populations from east and west Africa: comparison of microsatellite and allozyme loci. Heredity. 1996;77:192-200

72. Slatkin M. Estimating levels of gene flow in natural populations. Genetics. 1981;99:323-35.

73. Rasic G, Filipovic I, Weeks AR, Hoffmann AA. Genome-wide SNPs lead to strong signals of geographic structure and relatedness patterns in the major arbovirus vector, Aedes aegypti. BMC Genomics. 2014;15:275.

74. Campos M, Conn JE, Alonso DP, Vinetz JM, Emerson KJ, Ribolla PE. Microgeographical structure in the major neotropical malaria vector Anopheles darlingi using microsatellites and SNP markers. Parasites Vectors. 2017;10:76.

75. Pfeiler E, Flores-Lopez CA, Mada-Velez JG, Escalante-Verdugo J, Markow TA. Genetic diversity and population genetics of mosquitoes (Diptera: Culicidae: Culex spp.) from the Sonoran Desert of North America. ScientificWorld Journal. 2013;2013:724609.

76. Saraiva JF, Souto RNP, Scarpassa VM. Molecular taxonomy and evolutionary relationships in the Oswaldoi-Konderi complex (Anophelinae: Anopheles: Nyssorhynchus) from the Brazilian Amazon region. PLoS ONE. 2018;13:e0193591.

77. Kamgang B, Ngoagouni C, Manirakiza A, Nakoune E, Paupy C, Kazanji M. Temporal patterns of abundance of Aedes aegypti and Aedes albopictus (Diptera: Culicidae) and mitochondrial DNA analysis of Ae. albopictus in the Central African Republic. PLoS Negl Trop Dis. 2013;7:e2590.

78. Kang S, Jung J, Kim W. Population genetic structure of the malaria vector Anopheles sinensis (Diptera: Culicidae) sensu stricto and evidence for possible introgression in the Republic of Korea. J Med Entomol. 2015:52:1270-81.

79. Temu EA, Yan G. Microsatellite and mitochondrial genetic differentiation of Anopheles arabiensis (Diptera: Culicidae) from western Kenya, the Great Rift Valley, and coastal Kenya. Am J Trop Med Hyg. 2005;73:726-33.

80. Sumi A, Telan EF, Chagan-Yasutan H, Piolo MB, Hattori T, Kobayashi N. Effect of temperature, relative humidity and rainfall on dengue fever and leptospirosis infections in Manila, the Philippines. Epidemiol Infect. 2017;145:78-86.

81. Lai YH. The climatic factors affecting dengue fever outbreaks in southern Taiwan: an application of symbolic data analysis. Biomed Eng Online. 2018;17:148.

82. Bowman LR, Runge-Ranzinger S, McCall PJ. Assessing the relationship between vector indices and dengue transmission: a systematic review of the evidence. PLoS Negl Trop Dis. 2014;8:e2848.

83. Houe V, Bonizzoni M, Failloux AB. Endogenous non-retroviral elements in genomes of Aedes mosquitoes and vector competence. Emerg Microbes Infect. 2019;8:542-55.

84. Calvez E, Guillaumot L, Girault D, Richard V, O'Connor O, Paoaafaite T, et al. Dengue-1 virus and vector competence of Aedes aegypti (Diptera: Culicidae) populations from New Caledonia. Parasites Vectors. 2017:10:381.

85. Carvajal TM, Ogishi K, Yaegeshi S, Hernandez LFT, Viacrusis KM, Ho HT, et al. Fine-scale population genetic structure of dengue mosquito vector, Aedes aegypti and its association to local dengue incidence. BioRxiv. 2019. https://doi.org/10.1101/561621. Accessed 28 Apr 2019.

86. Zou L, Chen J, Feng X, Ruan S. Analysis of a dengue model with vertical transmission and application to the 2014 dengue outbreak in Guangdong Province, China. Bull Math Biol. 2018;80:2633-51.

87. Murillo D, Murillo A, Lee S. The role of vertical transmission in the control of dengue fever. Int J Environ Res Public Health. 2019;16:E803.

88. Gutierrez-Bugallo G, Rodriguez-Roche R, Diaz G, Vazquez AA, Alvarez M, Rodriguez $\mathrm{M}$, et al. First record of natural vertical transmission of dengue virus in Aedes aegypti from Cuba. Acta Trop. 2017;174:146-8.

89. Cruz LC, Serra OP, Leal-Santos FA, Ribeiro AL, SIhessarenko RD, Santos MA. Natural transovarial transmission of dengue virus 4 in Aedes aegypti from Cuiaba, State of Mato Grosso, Brazil. Rev Soc Bras Med Trop. 2015:48:18-25.

90. Thongrungkiat S, Wasinpiyamongkol L, Maneekan P, Prummongkol S, Samung Y. Natural transovarial dengue virus infection rate in both sexes 
of dark and pale forms of Aedes aegypti from an urban area of Bangkok, Thailand. Southeast Asian J Trop Med Public Health. 2012;43:1146-52.

91. Joshi V, Mourya DT, Sharma RC. Persistence of dengue-3 virus through transovarial transmission passage in successive generations of Aedes aegypti mosquitoes. Am J Trop Med Hyg. 2002;67:158-61.

92. Ant TH, Herd CS, Geoghegan V, Hoffmann AA, Sinkins SP. The Wolbachia strain wAu provides highly efficient virus transmission blocking in Aedes aegypti. PLoS Pathog. 2018;14:e1006815.

93. Pacidonio EC, Caragata EP, Alves DM, Marques JT, Moreira LA. The impact of Wolbachia infection on the rate of vertical transmission of dengue virus in Brazilian Aedes aegypti. Parasites Vectors. 2017;10:296.

94. Jiggins FM. The spread of Wolbachia through mosquito populations. PLoS Biol. 2017;15:e2002780.
95. Lu P, Bian G, Pan X, Xi Z. Wolbachia induces density-dependent inhibition to dengue virus in mosquito cells. PLoS Negl Trop Dis. 2012;6:e1754.

96. Hoffmann AA, Montgomery BL, Popovici J, Iturbe-Ormaetxe I, Johnson $\mathrm{PH}$, Muzzi F, et al. Successful establishment of Wolbachia in Aedes populations to suppress dengue transmission. Nature. 2011;476:454-7.

97. Zheng X, Zhang D, Li Y, Yang C, Wu Y, Liang X, et al. Incompatible and sterile insect techniques combined eliminate mosquitoes. Nature. 2019;572:56-61.

\section{Publisher's Note}

Springer Nature remains neutral with regard to jurisdictional claims in published maps and institutional affiliations.
Ready to submit your research? Choose BMC and benefit from:

- fast, convenient online submission

- thorough peer review by experienced researchers in your field

- rapid publication on acceptance

- support for research data, including large and complex data types

- gold Open Access which fosters wider collaboration and increased citations

- maximum visibility for your research: over $100 \mathrm{M}$ website views per year

At BMC, research is always in progress.

Learn more biomedcentral.com/submissions 